\title{
THE LOCAL EFFECT OF INTRA-UTERINE PROGESTERONE TREATMENT ON MYOMETRIAL ACTIVITY IN RABBITS
}

\author{
DAVID G. PORTER* \\ Department of Obstetrics and Gynecology, \\ Washington University, School of Medicine, St. Louis, Mo.
}

(Received 25th April 1967, revised 20th September 1967)

\begin{abstract}
Summary. The instillation of progesterone into the lumen of one uterine horn of unanaesthetized non-pregnant rabbits caused a more profound loss of intra-uterine pressure in the treated than in the placeboinjected control horn. The recovery of active pressure by the treated horn was significantly slower than by the control. The magnitude of the effect of progesterone, but not the rate of onset, was dose dependent. When progesterone was administered to one uterine horn of pregnant rabbits, asymmetrical delivery ensued, in which the control horns invariably expelled most of their foetuses before the treated horns commenced delivery. Autoradiographic study indicated that progesterone is very rapidly absorbed from the uterine lumen. The implication of these findings is discussed in relation to previous work.
\end{abstract}

\section{INTRODUCTION}

The theory of 'local' action of placental progesterone (Csapo, 1956) holds that, when this hormone is secreted within the uterus, it is able to reach the myometrium by a route which is more direct than the systemic circulation. The extent of such a local action should be affected by the distance from a placenta and thus lead to a hormonal and functional asymmetry.

Although there is no conclusive evidence of a local mechanism there is considerable circumstantial data (Goto \& Csapo, 1959; Daniel, 1960; Kuriyama \& Csapo, 1961; Zarrow, Wilson, Galdwell, Yochim \& Sawin, 1960; Jung, 1962; Schofield, 1963, 1966; Kumar, Wagatsuma, Sullivan \& Barnes, 1964) which indicates that the uterus of late pregnancy is functionally asymmetrical. Several workers (e.g. McGinty, Anderson \& McCullough, 1939; Jost, 1953) have shown that locally applied hormones exert a more pronounced effect upon near than upon distant target tissue.

Macedo-Costa \& Csapo (1959) were able to induce asymmetrical deliveries in rabbits with locally administered progesterone. If placentae were dislocated

* Lalor Fellow in Obstetrics and Gynecology. Present address: The Royal Veterinary College, Royal College St., London, N.W.1. 
unilaterally, or progesterone was injected intra-amniotically in one uterine horn only, the delivery from the bicornuate uterus was asymmetrical. In all cases intra-amniotic progesterone maintained pregnancy in the horn to which it was administered, and the delivery of the contents of the untreated horn was a clear example of functional asymmetry.

It therefore seemed appropriate to carry out a quantitative study of uterine activity. Such a study was made possible by recent advances in the technique of recording intra-uterine pressure in the intact conscious rabbit (Csapo, Takeda \& Wood, 1963). This technique was modified by attaching a catheter to the intra-uterine recording balloons, which allowed repeated administration of substances directly into the uterine lumina without further surgery. The combination of a recording system and a catheter for local treatment permitted quantitative analysis of the pharmacological reactivity of the experimental uterine horn, while the other horn in the same animal could be used as a control.

\section{MATERIALS AND METHODS}

New Zealand White rabbits were used weighing 3.5 to $4.5 \mathrm{~kg}$. Surgery was performed aseptically under sodium pentobarbitone and ether anaesthesia.

\section{Non-pregnant animals}

The endocrine status of the non-pregnant animals was standardized by ovariectomy. Through a mid-line laparotomy and a small incision in the ventral vaginal wall, a recording balloon (latex, $13 \mathrm{ml}$ capacity without stretch) attached to polyethylene tubing (external diameter: $1.55 \mathrm{~mm}$; internal: $0.88 \mathrm{~mm}$ ) was inserted together with an open-ended catheter into each uterine horn through the cervical canal. The catheters, made of tubing similar to the connecting tubes, were perforated with five lateral holes along their intra-uterine segment, to permit the distribution of injected material throughout the uterine cavity. The balloons and catheters were fixed by means of a suture in the antimesometrial wall which did not occlude the lumen. The tubes were led out through the wound, passed subcutaneously and brought to the exterior at the nape of the neck. The animals were allowed $48 \mathrm{hr}$ to recover from the surgery before the recording balloons were filled with water. The volume of the balloons was increased by small increments over 2 to 3 days until a steady-state of rhythmic pressure cycles was obtained without elevation of the resting pressure above $10 \mathrm{~mm} \mathrm{Hg}$. The final volume, which was always kept equal in the two horns, varied with the size of the uterus (as assessed at the time of surgery) but fell within the range of 2 to $10 \mathrm{ml}$. By connecting the recording catheters to Sanborn pressure transducers and a Sanborn recording instrument (model No. 964) the intra-uterine pressure in both horns could be monitored simultaneously, at intervals during several days. Only those animals were used in this study whose active intra-uterine pressure was similar in the two horns and exceeded $30 \mathrm{~mm} \mathrm{Hg}$.

The rabbits were divided into the following groups: Group I (five animals), treated with $0.15 \mathrm{mg}$ progesterone, administered into the uterine lumen during $3 \mathrm{hr}$; Group II (four animals), treated with $0.5 \mathrm{mg}$ progesterone, administered 
during $8 \mathrm{hr}$; Group III (two animals), one treated with $1.2 \mathrm{mg}$ progesterone during $12 \mathrm{hr}$, and one with $0.8 \mathrm{mg}$ progesterone during $18 \mathrm{hr}$.

All injections were made unilaterally. Progesterone (Upjohn) dissolved in sesame oil $(2.0 \mathrm{mg} / \mathrm{ml})$, was flushed into the experimental horn by means of $0.5 \mathrm{ml}$ sterile physiological saline, while in all cases the control horn received an identical volume of vehicle similarly flushed in with saline. Two animals were treated unilaterally with two doses of $0.5 \mathrm{ml}$ of sesame oil only, flushed in with 1 $\mathrm{ml}$ saline, in order to determine whether sesame oil exerts a pharmacological effect when administered intra-luminally to the uterus.

\section{Pregnant animals}

Seven rabbits were operated on either on the 27 th day or 28th day of pregnancy. Following bilateral ovariectomy a small balloon $(1.5 \mathrm{ml}$ capacity when unstretched) attached to polyethylene tubing, was inserted between the amniotic sac and the endometrium, in the lower segment of each horn. As in non-pregnant females a catheter to be used for local progesterone treatment was also inserted throughout the length of each horn. Both balloons and catheters were introduced through a small incision made in the uterine wall of the lower segment, thus leaving the cervix undisturbed. The foetus nearest the cervix in the horn selected for progesterone treatment was injected with $0.1 \mathrm{ml}$ of $1 \%$ Trypan blue solution, so that it might easily be recognized when expelled, thus indicating the onset of delivery from the experimental horn. Intra-uterine pressure was monitored. When a slight increment in pressure indicated the onset of the evolution of uterine activity, which routinely follows ovariectomy in the rabbit, progesterone $(2 \mathrm{mg} / \mathrm{ml}$, in sesame oil) was injected locally into the experimental horn, while the control horn received only the vehicle, sesame oil.

Intra-uterine pressure tracings were analysed by measuring the mean amplitude of active pressure cycles (AP) of $10 \mathrm{~mm} \mathrm{Hg}$ pressure or more, in 10-min samples of the records. The rate of rise in pressure was determined by dividing the AP by the time of pressure rise $\left(T_{r}\right), A P / T_{r}$ (Csapo, de Sousa-Filho, de Souza \& de Souza, 1966).

Three animals were given intra-luminal injections (unilaterally) of tritiated progesterone $(150 \mu \mathrm{c})$ and killed at intervals of 15,30 and 60 min after injection. Sections $(10 \mu)$ were made of both uterine horns using a cryostat and were picked up on gelatin-coated slides. After drying they were dipped in Ilford G5 emulsion and exposed for 7 to 10 days. The slides were then developed and stained with Azure blue. The distribution of radio-active material was then determined by the presence of silver grains in the tissue when examined microscopically.

\section{RESULTS}

\section{Non-pregnant rabbits}

The instillation of progesterone into the lumen of one uterine horn, while causing a reduction in the mean amplitude of the AP of both horns, caused a significantly greater effect in the treated than in the control horn. An example is illustrated in Plate 1. The treated horn differed from the control horn not only in the extent of reduction in AP but also in the time taken for the AP to 
return to normal values, following the cessation of progesterone treatment (Text-figs. 1 and 2). In Groups I and II the difference in the peak effect of the progesterone upon the two horns was statistically significant $(P<0.025)$ as was the difference in their recovery times $(P<0.025)$. In Group III the doses used were sufficiently high to cause virtually complete block so that in these instances the peak effect on both horns was the same. Nevertheless, both animals resembled the other groups in recovery, in that the control horns recovered more rapidly than the treated horns (Text-figs. 3 and 4 ).

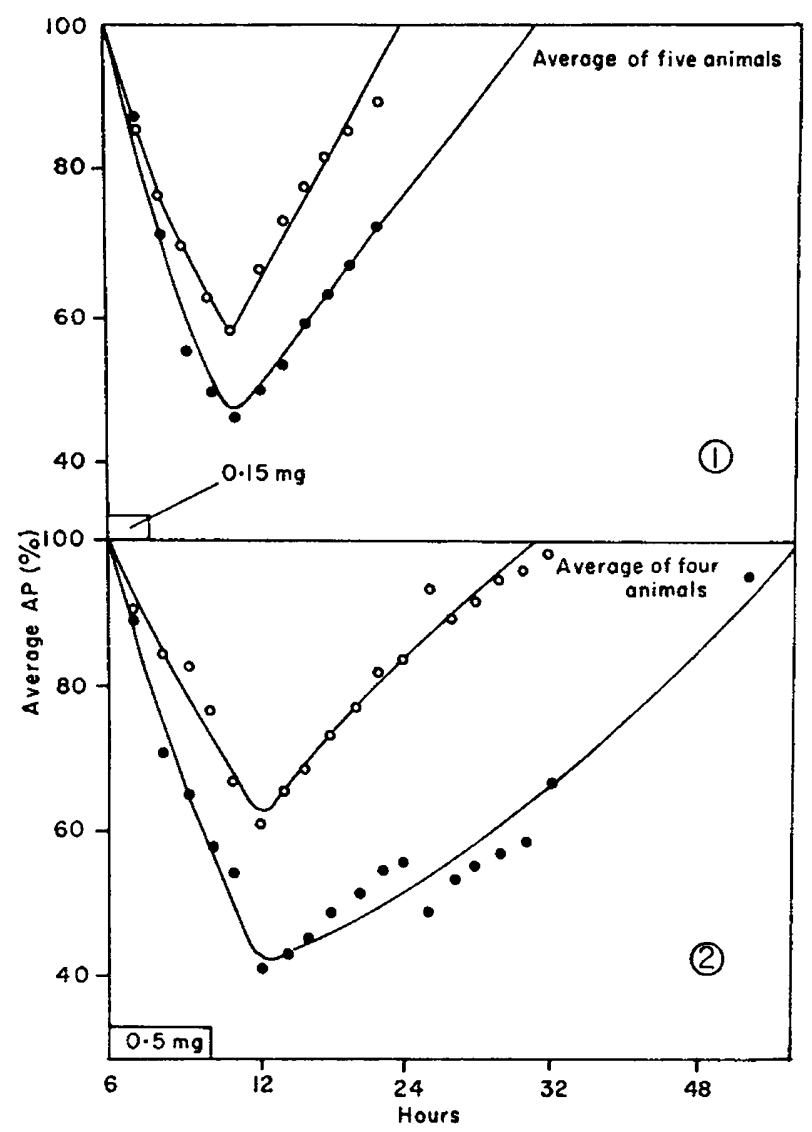

TExT-rigs. 1 and 2. Effect of unilateral progesterone treatment upon the mean amplitude of AP, expressed as a percentage of the pre-treatment mean. Open circles : control horn; closed circles: treated horn. Fig. 1: Treatment with an average dose of $0.15 \mathrm{mg}$ administered during $3 \mathrm{hr}$. Fig. 2: Treatment with an average dose of $0.5 \mathrm{mg}$ administered during $8 \mathrm{hr}$. Extreme right hand point of treated horns is from a single animal.

Text-figs. 1 to 4 illustrate that both the degree of the block and its time course are functions of the dose of progesterone administered. At an average dose of $0.15 \mathrm{mg}$ there was a $50 \%$ reduction in AP of the treated horn after $10 \mathrm{hr}$. At $0.5 \mathrm{mg} \mathrm{a} 60 \%$ reduction occurred after $12 \mathrm{hr}$, and at the 0.8 to $1.2 \mathrm{mg}$ dose range the reduction was more than $80 \%$, occurring between 12 and $24 \mathrm{hrs}$. While both the measurements and the data analysis are complex it would appear that the relationship between the dose of progesterone and the degree and time 
PIA'TE 1

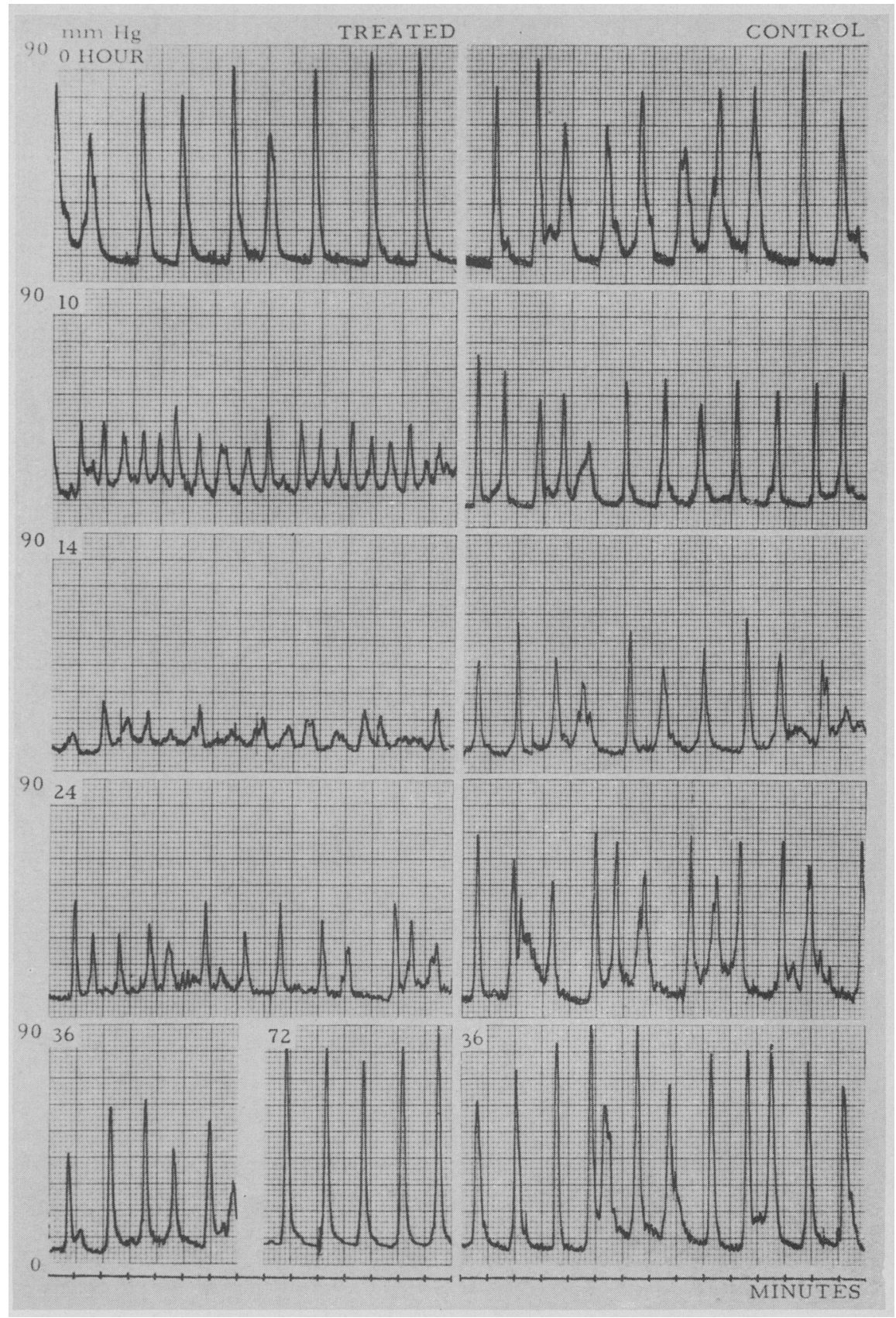

Intra-uterine pressure recordings. Effect of unilateral progesterone treatment $(0.5 \mathrm{mg} /$ $8 \mathrm{hr}$ ) upon uterine activity of a non-pregnant ovariectomized rabbit. I eft: treated; right column: control horn. Balloon volume $3 \mathrm{ml}$ in both horns. 
PLATE 2

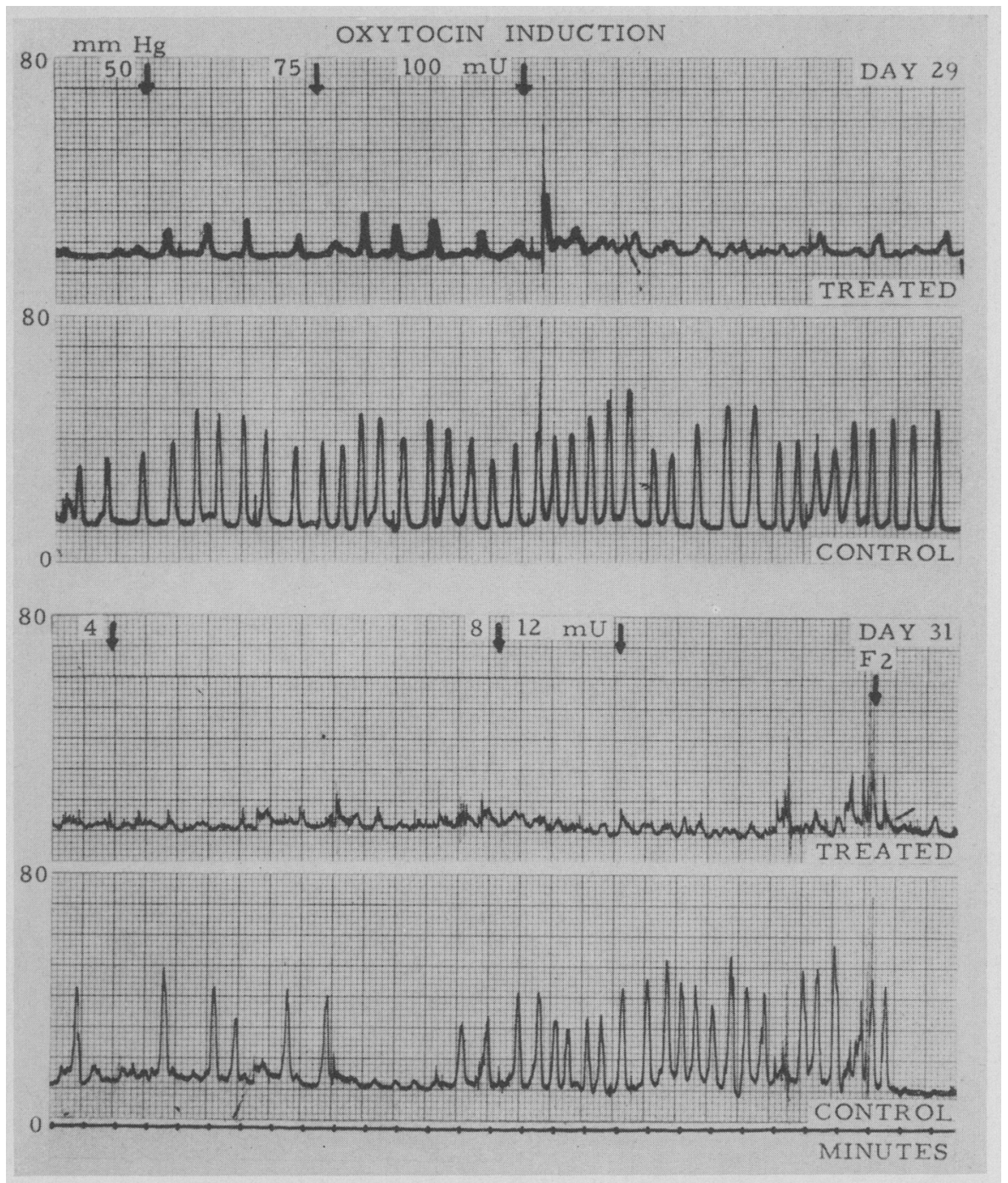

Intra-uterine pressure recordings from Rabbit 4 (Text-fig. 5). Pregnant rabbit; unilateral progesterone, Days 27 to $31,2 \cdot 8 \mathrm{mg}$. First foetus from control horn was delivered within 30 min of end of upper records and the second foetus as indicated (F2). Record shows the different responses to intravenous oxytocin of the two horns. 
course of the effect is linear. The difference in the peak effect, between the horns, was diminished as the dose increased but the difference in the rate of recovery remained. The difference between the two horns in the time required for $100 \%$ recovery was 10,20 and $48 \mathrm{hr}$, respectively, at the doses of $0.15,0.5$ and $1.2 \mathrm{mg}$. If the total dose was large $(0.8 \mathrm{mg})$ but the rate of administration

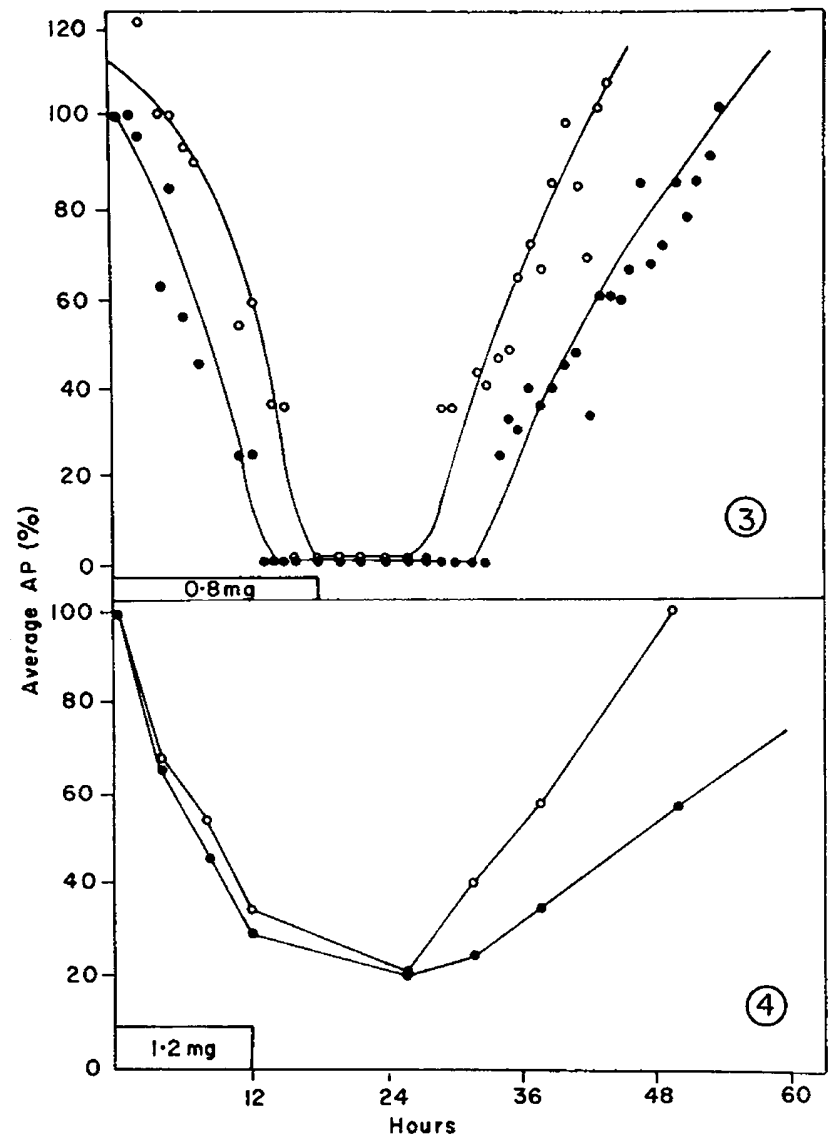

Text-Figs. 3 and 4. Effect of unilateral progesterone treatment upon the mean amplitude of AP, expressed as a percentage of the pre-treatment mean. Open circles: control horn; closed circles: treated horn. Fig. 3: Data from an animal treated with $0.8 \mathrm{mg}$ progesterone during $18 \mathrm{hr}$. Intra-uterine pressure was recorded continuously throughout the experiment. Fig. 4: Data from a rabbit treated with $1.2 \mathrm{mg}$ progesterone during $12 \mathrm{hr}$. Intra-uterine pressure was recorded at intervals indicated by points on the curve.

was low $(0.04 \mathrm{mg} / \mathrm{hr}$ ) (Text-fig. 3), the difference in the rapidity of the onset of the effect between the two horns appeared to be exaggerated compared with the 'large dose-high rate' treatment (compare Text-figs. 3 and 4), whereas the difference in recovery diminished, more closely resembling the type of recovery of the low dose group $(0.05 \mathrm{mg} / \mathrm{hr}$, Text-fig. 1$)$.

The frequency of the cyclic, spontaneous activity did not change consistently after local progesterone treatment. However, the decrease in the rate of rise of pressure $\left(\mathrm{AP} / \mathrm{T}_{\mathrm{r}}\right)$ in individual contraction cycles followed a time course comparable to that of the change in amplitude. 


\section{Pregnant rabbits}

Unilateral progesterone treatment, even at low doses of 1.1 to $2.8 \mathrm{mg}$, delayed both the evolution of spontaneous activity and the onset and progress of labour, and also depressed the oxytocin sensitivity of the treated horn as compared with the control horn. Although the evolution process of the control horns was slower than is characteristic of ovariectomized rabbits, it eventually culminated in delivery in all animals before the treated horns delivered. This was so in spite of the fact that in only one instance out of four was the

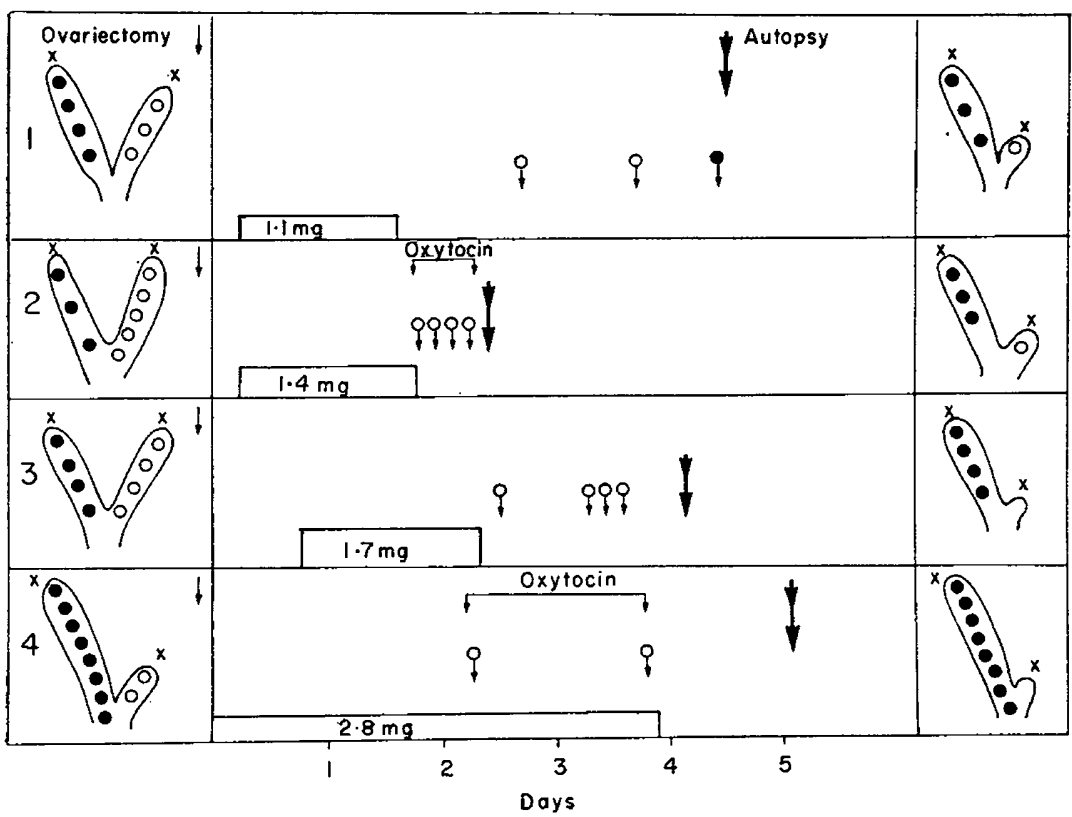

TExT-FIG. 5. Data from four 26/27-day pregnant rabbits treated with progesterone unilaterally after removal of both ovaries. Diagrams on left indicate contents of uterus at the time of surgery and on the right at the time of delivery of the first foetus from the treated horn or at autopsy. Attempts at inducing labour were made with intravenous oxytocin between the arrows shown in the cases of rabbits 2 and 4 . Rabbit 4 delivered two foetuses spontaneously and the remaining six from the progesterone treated horn in response to $40 \mathrm{mU}$ oxytocin, just prior to autopsy. Open circles: foetuses in control horns; closed circles : foetuses in treated horns. Circles with arrows : delivery. Progesterone dosage and period of administration are indicated by Figures and Boxes.

volume of the control horn (i.e. number of foetuses) greater than that of the treated horn (No. 3, Text-fig. 5). Indeed twelve out of fourteen foetuses had already been delivered by the control horns (Text-fig. 5 ) by the time the treated horns expelled the first foetuses.

The degree of functional asymmetry is further illustrated by the different response of the two horns to intravenous oxytocin (Plate 2).

The presence of the recording balloons and catheters in utero, and the local progesterone treatment, did not constitute a markedly unphysiological condition. This was indicated by the ability of the treated horn (rabbit 4), under oxytocin stimulation, to deliver its entire contents some $20 \mathrm{hr}$ after the control horn. 
Autoradiographic study of the uterine horns 15, 30 and $60 \mathrm{~min}$ after the unilateral intra-luminal administration of tritiated progesterone revealed that progesterone or its metabolites are rapidly absorbed and distributed by the systemic circulation. Evidence of radio-activity could be detected in both the endometrium and the myometrium of both horns $15 \mathrm{~min}$ after injection. That this absorption occurred from an apparently normal endometrium was confirmed by histological examination, since no denudation of the epithelium had occurred as the result of a recording balloon being present chronically in the uterine cavity. The technique revealed that labelled steroid penetrated the uterine wall and in some form reached the control horn.

\section{DISCUSSION}

The similarity between the nature and the kinetics of the effect of systemically administered progesterone (Allen \& Reynolds, 1935; Csapo \& Takeda, 1965) and the locally applied hormone is apparent in the above experiments. However, if the classical concept of endocrine function were applicable here, then unilateral progesterone treatment should produce a symmetrical effect in the two uterine horns, after being absorbed and distributed uniformly by the systemic circulation. In the present series, unilateral administration of progesterone always produced a functional asymmetry between the treated and control horns, in both the non-pregnant and pregnant animals. In non-pregnant animals the asymmetry was revealed in the form of a greater reduction of intra-uterine pressure in the treated than in the control horn, while in pregnant animals by the retention of foetuses in the treated horn after the untreated horn expelled its contents.

Since both uterine horns in all animals were subjected to the same treatment, except that only one received progesterone, it is clear that the asymmetry of function can only be explained on the basis that some of the hormone was distributed to the myometrium of the treated horn by some other route than the systemic circulation. These studies confirm the earlier findings of MacedoCosta \& Csapo (1959).

That the control horn shows some loss of amplitude in all experiments indicates that some progesterone was absorbed by the systemic circulation and was distributed to both horns. That it was not due to the effects of sesame oil is confirmed by the failure of the oil to alter uterine activity when administered alone. The difference between the two horns in the reduction of AP represents the proportion of the progesterone which reached the myometrium of the treated horn by some route other than through the systemic circulation. This proportion was responsible for supporting pregnancy in the treated horns while the control horns delivered twelve out of fourteen foetuses.

The kinetics of the experiments revealed that the degree of response and the recovery time were apparently proportional to the dose administered. However, it appears that, as the rate of progesterone administration was increased, the difference between the two horns in the onset of the effect was diminished, presumably due to an increase in the fraction of progesterone which was systemically distributed. Since this assumption is based upon the results from only 
two animals it requires confirmation. It is significant, however, that the rate at which the amplitude was lost, following progesterone treatment, was not accelerated by increasing the dose, even to the point of producing a total block. Since autoradiographic studies indicated that progesterone.probably reached the myometrium within minutes after injection, it would appear that a certain minimum time is required for the biological effect of progesterone to develop after the hormone has reached the uterine muscle. This time lag does not seem to be influenced by progesterone concentration. In an earlier study (Schofield, 1961) an attempt was made to reproduce the acute in-vitro effect of progesterone in the intact animal by intra-luminal application of the hormone. However, no acute effect could be elicited, illustrating that the in-vitro and in-vivo effects of progesterone are different. The present findings are thus in good agreement with this observation.

The study with autoradiography indicated that progesterone or its metabolites are absorbed very rapidly from the uterine lumen and distributed to the myometrium of both horns. These findings confirm the more quantitative study of Schofield (1961), who found that ${ }^{14} \mathrm{C}$-progesterone was absorbed from the lumen and distributed to the myometrium in greater concentration than to the endometrium. Furthermore, the amount of progesterone found in the control horn was $5 \%$, or less, than that found in the treated horn as estimated on the basis of the amount of radio-activity. While these findings are consistent with the functional asymmetry produced in the experiments of this series, the present autoradiography was carried out qualitatively so that comment on the quantitative distribution of radio-active progesterone is precluded.

The present experiments support Csapo's theory of the 'local' action of placental progesterone in that they demonstrate that such a 'local' effect can be induced with exogenous progesterone. However, they offer no proof that functional placentae actually exert a local effect upon the myometrium. Nevertheless, placentae, particularly deciduate placentae, are in a more intimate structural relationship with the overlying myometrium than an oil droplet in the uterine cavity. Therefore, if placentae secrete progesterone and there is evidence (Zander \& von Münstermann, 1954; Short \& Moore, 1959; Short \& Eckstein, 1961; Heap \& Deanesly, 1966; Lurie, Reid \& Villee, 1966; Asdell 1966) that at least some of them do, it would seem highly probable that an asymmetrical distribution of progesterone occurs naturally with the consequent asymmetry in the function of the uterus.

\section{ACKNOWLEDGMENTS}

I am indebted to Dr Arpad Csapo for his encouragement, and helpful criticism in preparing the manuscript. I wish to express my thanks also to $\mathrm{Dr}$ Sam Clark, Jr. of the Department of Anatomy, Washington University School of Medicine for providing the facilities for, and Robert Becker, B.A. for his assistance in carrying out, the autoradiography. My gratitude is due to the Lalor Foundation for their generous support.

This work has been supported by grant HDO1478 from the National Institutes of Health. 


\section{REFERENCES}

Allen, W. M. \& Reynolds, S. R. (1935) Crystalline progestin and inhibition of uterine motility in vivo. Science, 82, 155.

AsDELl, S. A. (1966) Evolutionary trends in physiology of reproduction. In: Comparative Biology of Reproduction in Mammals, p. 1. Ed. I. W. Rowlands. Academic Press, New York.

Csapo, A. I. (1956) Progesterone 'block'. Am. F. Anat. 98, 273.

Csapo, A., de Sousa-Filho, M. B., De Souza, J. C. \& de Souza, O. (1966) The effect of massive progestational hormone treatment on the parturient human uterus and the consequent reversible sterility. Fert. Steril. 17, 621.

Csapo, A. I. \& TAKEDA, H. (1965) Effect of progesterone on the electric activity and intra-uterine pressure of pregnant and parturient rabbits. Am. J. Obstet. Gynec. 91, 221.

Csapo, A. I., TAKEDA, H. \& Wood, C. (1963) Volume and activity of the parturient rabbit uterus. Am. F. Obstet. Gynec. 85, 813.

Daniel, E. E. (1960) Effect of the placenta on the electrical activity of the cat uterus in vivo and in vitro. Am. J. Obstet. Gynec. 80, 229.

Goto, M. \& Csapo, A. I. (1959) The effect of the ovarian steroids on the membrane potential of uterine muscle. F. gen. Physiol. 43, 455.

Heap, R. B. \& Deanesly, R. (1966) Progesterone in systemic blood and placentae of intact and ovariectomised pregnant guinea pigs. F. Endocr. 34, 417.

Jost, A. (1953) Problems of foetal endocrinology: The gonadal and hypophyseal hormones. Recent Prog. Horm. Res. 8, 379.

Jusa, H. (1962) Hormonal control of the conduction of the impulses in the myometrium. F. Obstet. Gynaec. Br. Commonw, 69, 1040.

Kumar, D., Wagatsuma, T., Sullivan, W. \& Barnes, A. C. (1964) Studies on the mechanism of action of progesterone on the human myometrium. Am. 7. Obstet. Gynec. 90, 1355.

Kurtyama, H. \& Csapo, A. (1961) Placenta and myometrial block. Am. J. Obstet. Gynec. 82, 592.

LURIE, A. O., REID, D. \& VILleE, G. (1966) The role of the fetus and placenta in maintenance of plasma progesterone. Am. F. Obstet. Gynec. 96, 670.

Macedo-Costa, L. \& Csapo, A. I. (1959) Asymmetrical delivery in rabbits. Nature, Lond. 184, 144.

McGinty, D. A., Anderson, L. P. \& McCullough, N. B. (1939) Effect of local application of progesterone on the rabbit uterus. Endocrinology, 24, 829.

Schofield, B. M. (1961) The acute effect of progestational compounds on intact rabbit myometrium. F. Physiol., Lond. 157, 117.

Schofield, B. M. (1963) The 'local' effect of the placenta on myometrial activity in the rabbit. $\mathcal{F}$. Physiol., Lond. 166, 191.

Schopiesd, B. M. (1966) The local influence of the placenta on myometrial activity. Mem. Soc. Endocr. $14,221$.

Short, R. V. \& Eckstein, P. (1961) Oestrogen and progesterone levels in pregnant rhesus monkeys. F. Endocr. 22, 15.

SHORT, R. V. \& MOORE, N. W. (1959) Progesterone in blood. Progesterone and 20a-hydroxy-pregn4-en-3-one in the placenta and blood of ewes. F. Endocr. 19, 288.

Zander, J. \& von MünstrRmann, A. (1954) Weitere Untersuchungen über Progesteron in Menschlichem Blut und Geweben. Klin. Wschr. 32, 894.

Zarrow, M. X., Wilson, M. S., Caldwell, A., Yochim, J. \& Sawin, P. B. (1960) Local action of placental progestogen on uterine musculature in the rabbit. Fert. Steril. 11, 370. 